\section{Psicologia Escolar \\ e Educacional}

ARTIGO

DOI: http://dx.doi.org/10.1590/2175-35392020217618

Elocid - e217618

\title{
ESTUDANTES COM TRANSTORNO DO ESPECTRO AUTISTA NO ENSINO SUPERIOR: ANALISANDO DADOS DO INEP
}

\author{
Solange Cristina da Silva ${ }^{1} \mathbb{D}$; Daniela Ribeiro Schneider ${ }^{1} \mathbb{D}$; Erikson Kaszubowski ${ }^{1} \mathbb{D}$; Adriano Henrique Nuernberg $^{1} \mathbb{D}$
}

\section{RESUMO}

Este artigo objetiva o mapeamento do perfil sociodemográfico dos estudantes com Transtorno do Espectro Autista (TEA) matriculados no ensino superior em 2016 a partir dos microdados do INEP. De abordagem quantitativa, configura-se numa pesquisa de levantamento de dados de natureza descritiva. Os resultados indicam que havia 546 (sem imputação) ou 1.217 (com imputação) de estudantes autodeclarados com TEA (alunos únicos), correspondendo a $0.01 \%$ do total de estudantes matriculados em 2016. Esses estudantes são predominantemente: brancos (37\% sem ou $51 \%$ com imputação), do sexo masculino (61,5\% sem ou $72.3 \%$ com imputação) e residentes no Sudeste (33\% sem imputação) ou Nordeste (50\% com imputação). Dados que possibilitam o conhecimento das diferentes características que se cruzam e ajudam na manutenção das barreiras de acesso e permanência acadêmica, além de trazerem reflexões acerca da interseccionalidade de marcadores sociais, contribuindo para a busca do aprimoramento de políticas públicas para esta população.

Palavras-chave: Acessibilidade; autismo; ensino superior.

\section{Students with autism spectrum disorder in higher education: analyzing INEP data}

\begin{abstract}
This article aims to map the socio demographic profile of students with Autistic Spectrum Disorder (ASD) enrolled in higher education in 2016 from the INEP microdata. With a quantitative approach, it is configured in a survey of descriptive data. The results indicate that there were 546 (no imputation) or 1,217 (with imputation) of self-declared students with ASD (single students), corresponding to $0.01 \%$ of the total enrolled students in 2016. These students are predominantly: white ( $37 \%$ without or $51 \%$ with imputation), male ( $61.5 \%$ without or $72.3 \%$ with imputation) and residents in the Southeast (33\% without imputation) or Northeast (50\% with imputation). Data that enable the knowledge of the different characteristics that intersect and help maintain the barriers of access and academic permanence, and bring reflections on the intersectionality of social markers, contributing to the pursuit of improving public policies for this population.
\end{abstract}

Keywords: Accessibility; autism; higher education.

\section{Estudiantes con trastorno del espectro autista en la enseñanza universitaria: analizando datos del Inep}

\section{RESUMEN}

Este artículo tiene por objetivo el mapeo del perfil sociodemográfico de los estudiantes con Trastorno del Espectro Autista (TEA) matriculados en la enseñanza universitaria en 2016 a partir de los micro-datos del INEP. De abordaje cuantitativo, se configura en una investigación de recopilación de datos de naturaleza descriptiva. Los resultados indican que había 546 (sin imputación) o 1.217 (con imputación) de estudiantes auto-declarados con TEA (alumnos únicos), correspondiendo al $0.01 \%$ del total de estudiantes matriculados en 2016 . Esos estudiantes son predominantemente: blancos (el $37 \%$ sin o el $51 \%$ con imputación), del sexo masculino (el 61,5\% sin o el $72.3 \%$ con imputación) y residentes en el Sudeste (el 33\% sin imputación) o Nordeste (el 50\% con imputación). Datos que posibilitan el conocimiento de las diferentes características que se cruzan y ayudan en la manutención de las trabas de acceso y permanencia académica, además de traer reflexiones acerca de la interseccionalidad de marcadores sociales, contribuyendo para la búsqueda del perfeccionamiento de políticas públicas para esta populación.

Palabras clave: Accesibilidad; autismo; enseñanza universitaria.

1 Universidade do Estado de Santa Catarina - Florianópolis - SC - Brasil; solangecsilva66@gmail.com; danischneiderpsi@gmail. com; erikson84@yahoo.com.br; adrianoh@cfh.ufsc.br 


\section{INTRODUÇÃO}

Há um crescente no ingresso de estudantes com deficiência no ensino superior, resultado do processo histórico de luta por direitos e contra a concepção da pessoa com deficiência como incapaz e deficitária do ponto de vista funcional e social. Esse processo de luta por direitos vem se materializando desde as políticas de inclusão que surgiram no Brasil entre o final da década de 1980 e o início da de 1990, com a Constituição Federal de 1988 (Brasil, 1988), inicialmente com ênfase no sistema regular de ensino na educação básica, numa proposta de integração e, posteriormente, numa proposta de inclusão. Outros documentos nacionais objetivam assegurar o direito à educação como a LDB - Lei de Diretrizes e Bases da Educação (Lei n. 9.394/96, 1996)-, o Plano Nacional de Educação para Todos (Brasil, 2001) e a Política Nacional de Educação Especial na Perspectiva da Educação Inclusiva (Brasil, 2008), dentre outros.

O processo de consolidação de políticas públicas visando a inclusão educacional de pessoas com deficiência se fortalece, principalmente, com a promulgação da Convenção Internacional sobre os Direitos das Pessoas com Deficiência (Convenção da ONU) e seu Protocolo Facultativo, ratificada com força de Emenda Constitucional por meio do Decreto Legislativo $n^{\circ} 186 / 2008$ (2008) e do Decreto n. 6.949/2009 (2009). Nessa Convenção, consolida-se o termo "pessoa com deficiência", que será usado ao longo desse texto por estar em consonância com a compreensão de deficiência na perspectiva do modelo social e em contraposição ao modelo médico, concebendo a deficiência como uma construção histórica e social, perspectiva esta, base desta pesquisa.

No rol de "pessoas com deficiência" foram incorporadas, a partir da aprovação da Lei $n^{\circ} 12.764 / 2012$ (2012) - Política Nacional de Proteção dos Direitos da Pessoa com Transtorno do Espectro Autista-, as pessoas com TEA, que passam a ter garantidos todos os direitos voltados a esse grupo.

A inclusão das pessoas com deficiência no Ensino Superior é fortalecida por outros aportes legais, como a Portaria n. 1.679/1999 (1999), que estabeleceu requisitos de acessibilidade ao ensino de pessoas com deficiência para a autorização e reconhecimento de curso e credenciamento de instituições; o Decreto $\mathrm{n}$. 3.298/1999 (1999), que, em seu Art. 27, normatiza sobre o dever das instituições de ensino superior de oferecer adaptações de provas e apoios necessários aos estudantes com deficiência, bem como propõe alteração curricular para a inclusão de conteúdo, itens ou disciplinas relacionadas à pessoa com deficiência; o Decreto n. 5.296/2004 (2004), que assegura a inclusão do desenho universal e normas da ABNT de acessibilidade nos currículos das instituições de ensino profissional, tecnológico e superior nas áreas de engenharia, arquitetura e afins, bem como fixa normas para os estabelecimentos visando à concessão de autorização para abertura, funcionamento e renovação de curso; o Decreto n. 7.612/2011 (2011), que institui o Plano Nacional dos Direitos da Pessoa com Deficiência - Plano Viver sem Limite, que preconiza "promover, por meio da integração e articulação de políticas, programas e ações, o exercício pleno e equitativo dos direitos das pessoas com deficiência" (n.p.); o Plano Nacional de Educação (decênio 2014-2024), que determina diretrizes, metas e estratégias para a política educacional para o período de dez anos; a Lei n. 13.005/2014, que em seu artigo 4으, preconiza que o poder público buscará a ampliação do rol das pesquisas com fins estatísticos para disponibilizar informações detalhadas sobre o perfil das populações com deficiência de quatro a dezessete anos.

Das políticas governamentais para o acesso e permanência das pessoas com deficiência no ensino superior, recentemente implementadas, destaca-se o Programa Universidade para Todos (ProUni), instituído pela Lei $n^{\circ} 11.096 / 2005$ (2005), cujo objetivo é destinar bolsas de estudos às pessoas com deficiência em IES privadas (Art. 2ㅇ) e percentual de bolsas de estudo destinado à implementação de políticas afirmativas de acesso ao ensino superior de pessoas com deficiência ou de autodeclarados indígenas e negros (Art. 7으); o Programa de Acessibilidade na Educação Superior (Incluir), Edital INCLUIR 04/2008 (Brasil, 2008), que propõe ações para garantir o acesso pleno de pessoas com deficiência em instituições federais de ensino superior.

Apesar do compromisso crescente na adoção de políticas públicas voltadas à inclusão e ao aumento de matrículas das pessoas com deficiência, há uma lacuna na efetivação dessas políticas, demonstrado na comparação com a população geral universitária matriculada nas Instituições de Ensino Superior (IES), no qual representam menos de $1 \%(0,4 \%$ em 2015) do total de matrículas (Martins, Leite, \& Ciantelli, 2018).

No tocante ao estudante com TEA, esse número cai consideravelmente, denunciando que há desafios e barreiras de acesso significativas que precisam ser pesquisadas para se propor mudanças e ampliação das políticas públicas visando a igualdade de acesso e o cumprimento de direitos já conquistados. Para tanto, faz-se necessário conhecer esse público com TEA que acessa o ensino superior. Essa demanda foi a propulsora desta pesquisa sobre o perfil sociodemográfico dos estudantes com TEA no ensino superior.

A perspectiva é que os dados desta pesquisa, alinhados com as matrizes teóricas adotadas, possam contribuir na compreensão do perfil dos estudantes com autismo que acessam o ensino superior e, com isso, obter um instrumento de reflexão para a elaboração de políticas públicas que ampliem o acesso e a permanên- 
cia desse grupo no espaço acadêmico.

\section{METODOLOGIA}

Trata-se de uma investigação de natureza quantitativa, com dados indiretos, pois foram coletadas informações referentes aos estudantes com TEA identificados no INEP pelas variáveis "Autismo Infantil" e "Síndrome de Asperger" (nomenclatura que se refere ao DSM-IV) a partir dos microdados do Censo de Educação Superior do INEP referente ao ano 2016 (INEP, 2017). O Instituto Nacional de Estudos e Pesquisas Educacionais Anísio Teixeira - INEP realiza o Censo da Educação Superior, que se refere a um "levantamento de âmbito nacional realizado anualmente pela Diretoria de Estatísticas Educacionais em todas as Instituições de Educação Superior, públicas e privadas, do país" (INEP, 2016, p. 3). No documento anual, os dados são divididos em: Dados da Instituição de Ensino Superior (IES), Dados do Curso, Dados do Aluno e Variáveis Derivadas.

Por se fixar ao perfil do referido censo disponível, esse levantamento documental configura-se como um recorte transversal para a apresentação das variáveis já ocorridas relacionadas ao fenômeno acessibilidade. 0 acesso ao objeto de estudo, por ser realizado de maneira indireta, com uso de fontes documentais eletrônicas oficiais disponibilizadas pelo INEP para acesso público em forma de registros estatísticos, configura a pesquisa como documental. A pesquisa documental é aquela cuja fonte restringe-se à coleta de dados em documentos, escritos ou não, que podem ser acessados no momento ou depois em que o fato ou fenômeno ocorre (Lakatos \& Marconi, 2005). A escolha desse documento para a pesquisa se justifica por trazer dados nacionais dos estudantes com deficiência matriculados no ensino superior, seu perfil, forma de ingresso e as características das instituições acessadas.

As variáveis utilizadas para caracterizar o perfil sociodemográfico dos estudantes com TEA foram: Sexo, Idade do aluno, Cor/Raça e Estado e Região da IES onde o aluno está matriculado. Os termos "Cor/Raça" e "Aluno" são usados no documento do INEP. Manter-se-á o uso destes quando se referirem aos dados do INEP ou em citações, do contrário serão utilizados os termos "etnia" e "estudantes", por serem considerados mais adequados e atualizados.

A identificação dos estudantes com TEA se deu por duas vias. A primeira foi baseada na informação contida nas variáveis do censo que indicam se o estudante se autodeclarou com Autismo Infantil ou Síndrome de Asperger. Como essas duas variáveis possuem muitos dados faltantes, os dados dos censos dos anos anteriores foram utilizados para imputação, utilizando-se a estratégia de preenchimento last value carried forward (último valor válido carregado adiante). Todos os estudantes que se identificaram pelo menos uma vez com
Autismo Infantil ou Síndrome de Asperger entre 2011 e 2016 e que continuaram com qualquer situação de matrícula em 2016, identificados ou não com TEA nesse ano, foram incluídos na análise por meio dessa estratégia de imputação. O cruzamento entre diferentes anos é possível em função da identificação dos alunos com um código único entre todos os censos. Essa estratégia de análise foi utilizada em função de constatar fragilidade nos dados divulgados pelo INEP, sendo esta uma limitação do estudo.

Os dados das variáveis de perfil foram analisados considerando os dois conjuntos de dados: com base na imputação baseada nos anos anteriores e considerando apenas os dados do censo de 2016. Foi realizada a análise descritiva das informações de perfil utilizando a contagem de casos e a frequência relativa, sumarizados sob a forma de tabelas, gráficos de barras e mapas.

O projeto de pesquisa do qual este estudo faz parte foi encaminhado e aprovado pelo Comitê de Ética em Pesquisa - CEP/CONEP, sediado em uma universidade pública situada no Estado de Santa Catarina e seguiu todas as recomendações estabelecidas pelo Conselho Nacional de Saúde, por meio da Resolução n. 510/2016 e complementares.

\section{RESULTADOS}

Utilizando apenas as informações constantes no Censo referente ao ano de 2016, havia 546 estudantes no ensino superior com TEA, correspondendo a um total de 614 matrículas, independente da condição de matrícula (matriculado, desvinculado, trancado, falecido, formado). Com a imputação dos dados dos anos anteriores, o número de estudantes com TEA em 2016 subiu para 1.217 alunos únicos e 1.368 matrículas. Do total de alunos únicos, 73,2\% (891 - com imputação) e 52,4\% (286 - sem imputação) se identificaram com Autismo Infantil; 29,6\% (360 - com imputação) e 49,6\% ( 271 - sem imputação) se identificaram com Síndrome de Asperger; e 2,8\% (34 - com imputação) e 2,0\% (11 - sem imputação) foram registrados com ambos os diagnósticos.

A maioria dos estudantes com TEA são do sexo masculino, correspondendo a 61,5\% (748 - com imputação) e $72.3 \%$ (395 - sem imputação) do total. Estudantes do sexo feminino correspondem a 38.5\% (469-com imputação) e $27.7 \%$ (151 - sem imputação) do total de estudantes com TEA.

Com relação à cor/raça, referentes ao total de estudantes (dados únicos), o censo indica a primazia da cor/ raça branca, sendo: Amarela: 151.218 (1,46\%); Branca: 3.769.987 (36,50\%); Indígena: 59.617 (0,58\%); Parda: 2.350.409 (22,76\%); Preta: 592.584 (5,74\%); Não declarou: 3.157 .436 (30,57\%) e Não dispõe da informação: 246.072 (2,38\%). Primazia esta que se repete nos dados dos estudantes com TEA, sendo: a) com imputação: 
Amarela: 154 (13\%), Branca: 454 (37\%), Indígena: 6 (0.49\%), Parda: 363(30\%), Preta: 140 (12\%), Aluno não quis declarar: 94 (7.7\%), Não dispõe da informação: 6 (0.49\%); e b) sem imputação: Amarela: 6 (1.1\%), Branca: 277 (51\%), Indígena: 1 (0.18\%), Parda: 165 (30\%), Preta: 37 (6.8\%), Aluno não quis declarar: 57 (10\%) e Não dispõe da informação: 3 (0.55\%).

Em termos regionais, a Figura 1 apresenta a distribuição de estudantes com TEA nas cinco regiões do país. Para esta variável, o uso dos dados imputados traz uma mudança considerável para a distribuição entre as regiões, mudando a região com maior número de alunos com TEA do Sudeste para o Nordeste.

Ao considerar a distribuição por Estado, novamente os dados imputados se mostram diferentes dos dados sem imputação, como pode ser visualizado na Figura 2. Com a imputação, o maior número de estudantes com TEA localiza-se na Bahia, com $36 \%$ do total (422 alunos), mas esse estado possui apenas 10 alunos com TEA (1.8\%) nos dados do censo 2016. Sem imputação, o Estado com maior proporção de alunos com TEA é o Piauí (81 alunos, 15\%).

A média da idade dos estudantes do ensino superior

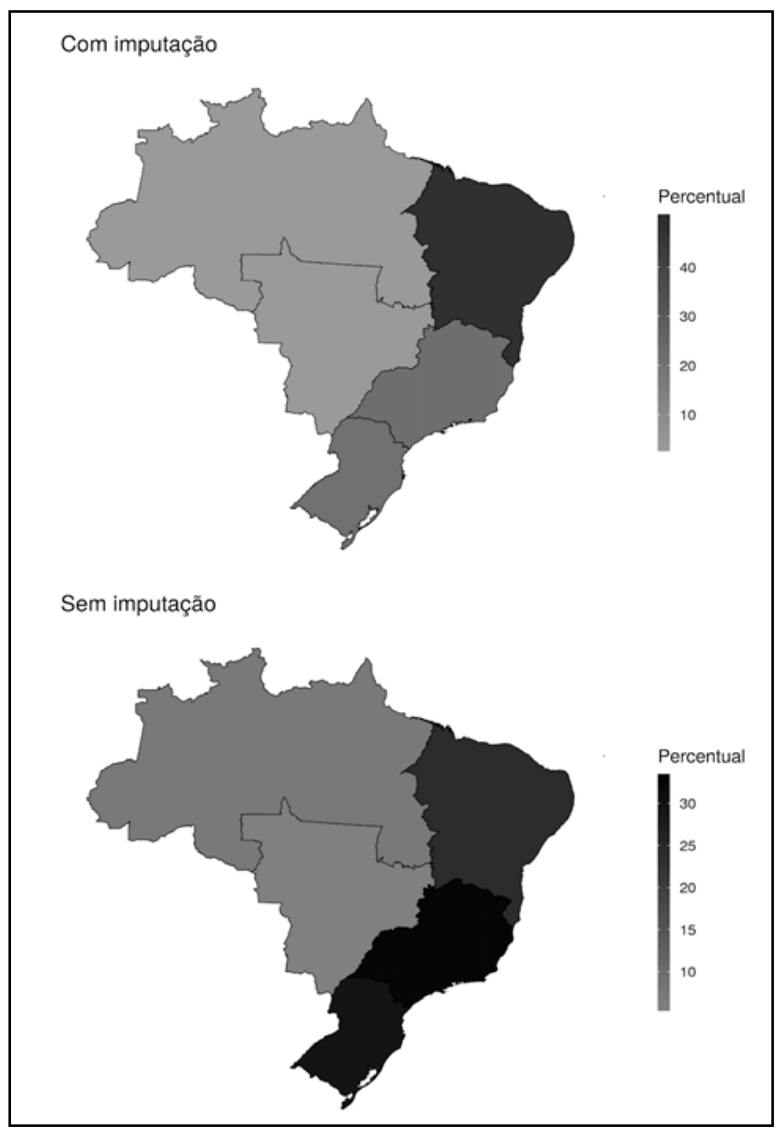

Figura 1. Mapa das Regiões do Brasil indicando a proporção do total de alunos com TEA em cada região: (a) com imputação; (b) sem imputação. matriculados em 2016 é de 27,6 anos ( $D P=8,45)$. Para os alunos com TEA, as informações sobre a idade são apresentadas na Figura 3. Há uma pequena diferença de dois anos na média de idade entre dados imputados ( 27 anos) e não imputados ( 25 anos), acompanhada de uma pequena mudança no desvio-padrão. A forma funcional, com assimetria positiva, permanece relativamente igual entre os dois conjuntos de dados.

\section{DISCUSSÃO}

Para analisar os dados da pesquisa, parte-se da premissa de que o autismo é uma característica da diversidade humana, não compreendido como um problema a ser resolvido, mas como uma característica cuja intersecção com diversas outras características corporais, sociais etc., formam a subjetividade do sujeito. Nesse sentido, é importante conhecer os diferentes marcadores sociais que constituem os estudantes com TEA que acessam o ensino superior e suas intersecções na relação com o meio, as quais podem criar ou fortalecer desigualdades e resultar em barreiras no processo acadêmico.

Nos dados obtidos pelo mapeamento do perfil de estudantes com TEA matriculados no ensino superior

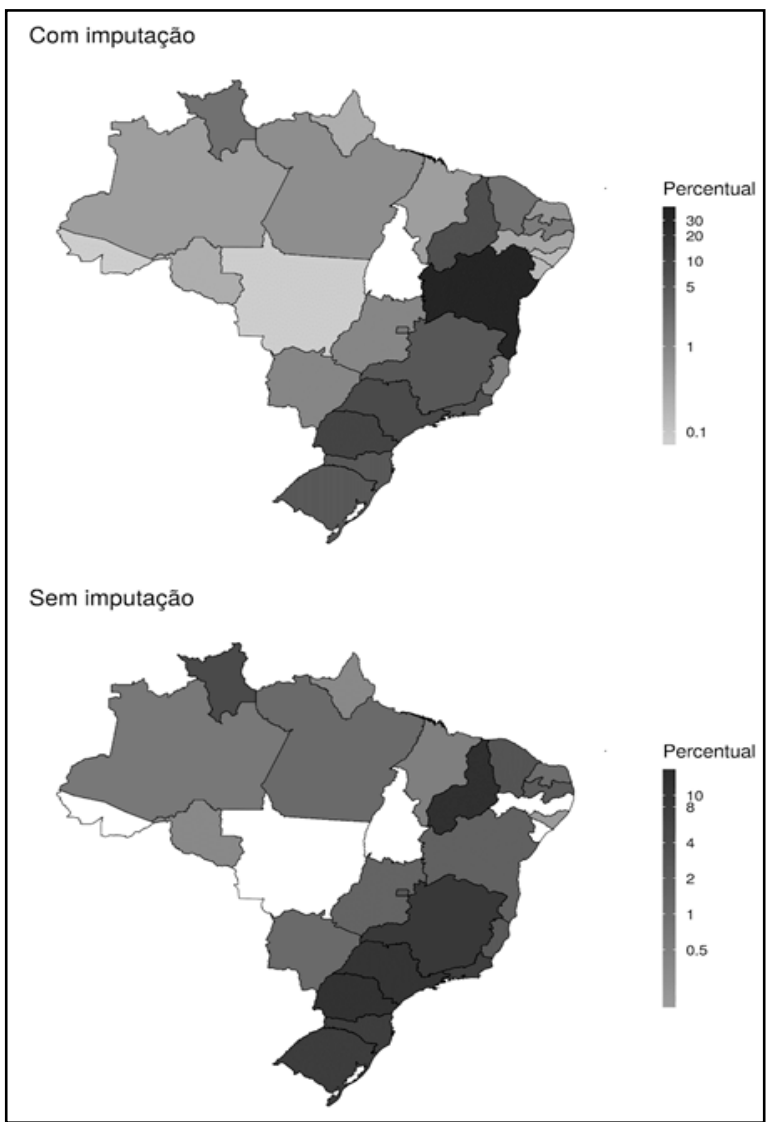

Figura 2. Mapa dos Estados do Brasil indicando a proporção do total de alunos com TEA referente a cada estado: (a) com imputação; (b) sem imputação. 


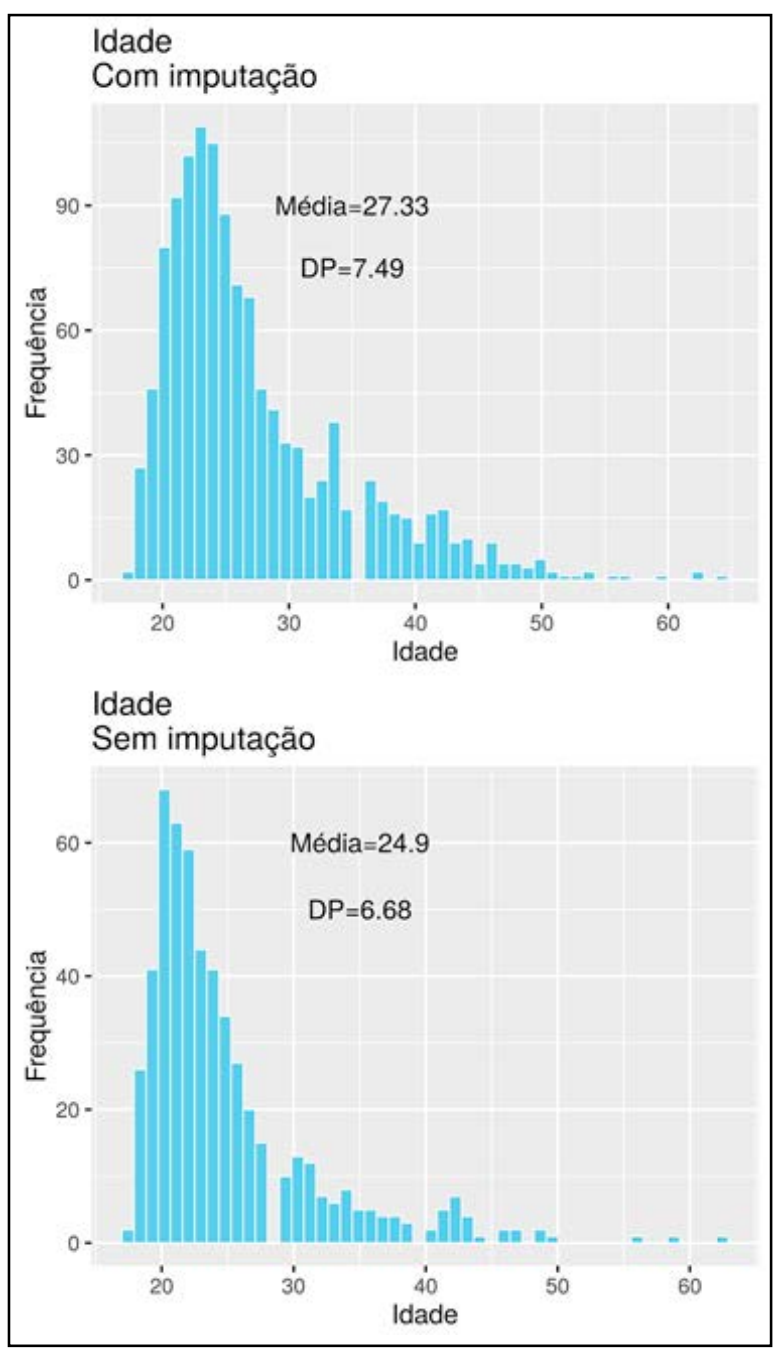

Figura 3. Histogramas da distribuição da idade (com média e desvio-padrão) dos alunos com TEA no ensino superior: (a) com imputação; (b) sem imputação.

em 2016 por meio do Censo do INEP (INEP, 2017), constata-se que, mesmo com todo o aporte legal que obriga o acesso de estudantes com deficiência e superdotação ao ensino superior, conforme mencionado na introdução deste artigo, ainda é exígua a quantidade desse público na academia, correspondendo $0,43 \%$ do total de estudantes matriculados em 2016, e destes 0,005\% autodeclarados com TEA (INEP, 2017).

Ao considerar o método de imputação utilizado na coleta dos dados, há um aumento considerável de estudantes matriculados, o que não se reflete na porcentagem de ingressos desses estudantes. Faz-se necessário esclarecer que há uma fragilidade nos dados trabalhados na análise. A discrepância dos dados sem imputação em relação aos dados com imputação não dá indícios para afirmações em relação ao motivo que leva a essa discrepância, mas permite questionar que é preciso um maior controle e orientação das IES sobre esse preenchimento e aprimoramento na análise para obtenção de dados mais fidedignos.

Em relação ao ingresso de estudantes com deficiência no ensino superior, Silva (2016), ao comparar a evolução das matrículas na universidade no período de 2010 a 2014 por meio do Censo da Educação Superior disponibilizados pelo INEP, notou que, embora ainda incipiente (representando $0,43 \%$ dos alunos que frequentam a ensino superior), houve significativo avanço no acesso de pessoas com deficiência no ensino superior, expressado pelo aumento de 20.287 para 33.377 em cinco anos. Isso significou um aumento de $64,52 \%$ diante do aumento de $22,57 \%$ do público geral que acessou a universidade nesse período. Esse fato denota uma gradativa inserção de estudantes com deficiência no ensino superior, mas ainda se destaca a lacuna no tocante à sua inclusão universitária, menos de $1 \%$ da população em geral matriculada no ensino superior (Silva, 2016). Pode-se dizer que essa gradativa inserção foi resultado das políticas voltadas à acessibilidade, a exemplo do Programa Incluir (MEC, 2008). Entretanto, as políticas de inclusão necessitam ser avaliadas, meIhoradas e ampliadas.

Sobre a idade de ingresso dos estudantes com TEA, é notória a constatação que eles acessam mais tardiamente o ensino superior em comparação aos estudantes neurotípicos ${ }^{1}$. O fato do enfrentamento de barreiras no ingresso no ambiente escolar desde a educação básica se reflete ao adiamento do ingresso ao ensino superior, soma-se a isso as barreiras de ingresso como provas e ambiente inadequados.

Com relação ao sexo dos estudantes, a proporção de homens e mulheres matriculados no ensino superior em 2016 (dados únicos) corresponde a 56,09\% (5.792.709) do sexo feminino e $43,91 \%$ (4.534.614) do sexo masculino, contrariamente à proporcionalidade de estudantes diagnosticados com TEA matriculados no mesmo ano, pois a maioria é do sexo masculino. Esse dado coaduna com os registros que indicam que os meninos com TEA são maioria em relação às meninas. Os dados registrados pela APA (2014) trazem a informação de que a proporcionalidade de prevalência de gênero em pessoas com TEA é de 1:4, ou seja, uma menina para cada quatro meninos com TEA. Entretanto, os dados apresentados nessa pesquisa divergem da proporcionalidade 1:4, visto que, ao considerar os dados com imputação dos estudantes com TEA matriculados no ensino superior em 2016, a proporção é de 1:1.59 (1 estudante do sexo feminino para cada 1.59 do sexo masculino) e pelos dados sem imputação é de 1:2.6 (1 estudante do sexo feminino para cada 2.6 do sexo masculino).

Embora em resultados de pesquisas a maioria mas-

\footnotetext{
${ }^{1}$ Neurotípico (NT) é a pessoa que possui "um estilo de funcionamento neurocognitivo que se enquadra nos padrões sociais dominantes de "normal" (Walker, 2014. n.p.).
} 
culina seja constatada na população com TEA, esse fato é questionado por outros estudos que apontam uma propensão a se ignorar o diagnóstico ou um diagnóstico equivocado quando se refere ao sexo feminino. Um exemplo é a pesquisa de Dworzynski, Ronald, Bolton e Happé (2012, p. 792), na qual afirmam que "na ausência de problemas intelectuais ou comportamentais adicionais, as meninas são menos propensas que os meninos a cumprir critérios diagnósticos para TEA com níveis equivalentemente altos de traços de autismo", e esse fato pode trazer "viés de gênero no diagnóstico ou adaptação/compensação genuinamente melhor em meninas". Dean, Harwood e Kasari (2017), em pesquisa sobre comportamentos sociais em crianças com TEA relacionados ao gênero, constatam que as meninas são propensas a "camuflar" seus sintomas de TEA, imitando comportamentos sociais para enfrentar os desafios. Apesar da camuflagem parecer protetora num primeiro momento, dificulta o diagnóstico e consequentemente o apoio pela intervenção.

Saxe (2017, p. 157) compreende que, numa experiência qualitativamente diferente do homem, as mulheres com deficiência estão em desvantagem por conta das seguintes questões: taxas extremamente baixas de emprego, violência doméstica, agressão sexual, dentre outras e que mulheres com deficiências de desenvolvimento "são frequentemente vítimas de abuso inqualificável". A autora defende que as mulheres com TEA têm três identidades, as quais contribuem para a vivência das barreiras: 1) serem do sexo feminino, gênero que enfrenta mais obstáculos e subjugação; 2) terem deficiência, num mundo em que grande parte das pessoas não tem e vive numa relação assimétrica de poder com seus iguais, enfrentando, assim, vários obstáculos para serem totalmente incluídas em suas comunidades e; 3 ) serem mulheres com autismo, uma vez que são a minoria nas pesquisas, nas práticas baseadas em pesquisa e a comunidade de pessoas com TEA, em grande parte, centra-se no sexo masculino. Isso faz com as mulheres com TEA sejam triplamente oprimidas.

Grande parte das políticas sociais para a promoção das igualdades, as quais mencionam as categorias discriminadas socialmente como a de gênero, não inclui a deficiência no debate e no cruzamento com outras categorias. Em acordo a essa constatação, Cerchiari e Paganelli (2018) relatam que o Comitê da ONU sobre os Direitos das Pessoas com Deficiência (CRPD) ao considerar que, de modo geral, as políticas para mulheres não mencionam deficiência e as políticas voltadas a deficiência têm a mesma postura em relação à questão de gênero e reconhecer a baixa repercussão do artigo 6o da Convenção dos Direitos das Pessoas com Deficiência, que trata dos direitos das meninas e mulheres com deficiência, lançou em 2016, um documento complementar", intitulado "General comment No. 3 (2016),
Article 6: Women and girls with disabilities" (UN, CRPD, 2016). Esse documento visa fornecer orientações para que se possa revisar e dar suporte para o estabelecimento de políticas e práticas para a garantia dos direitos das meninas e mulheres com deficiência (Cerchiari \& Paganelli, 2018).

Sendo assim, no aspecto gênero e deficiência, constatou-se maior número de estudantes do sexo masculino em relação ao sexo feminino que acessam o ensino superior. O motivo que leva a essa primazia masculina, pode-se hipotetizar algumas explicações com a de considerar a existência de uma subnotificação de mulheres com TEA; ou a dimensão histórico-social de que se dá maior valor à educação de meninos do que de meninas, consequentemente poucas conseguem acessar o ensino superior; ou, ainda, pelo caráter de maior vulnerabilidade das mulheres, para que elas não sejam incentivadas a ocupar espaços sociais como a Universidade, etc. Seriam necessárias outras pesquisas com foco nessa nuance para esclarecer os motivos geradores dessa primazia masculina. Todavia, mesmo em minoria, as estudantes do sexo feminino devem ser consideradas em sua especificidade e singularidade. Deve-se, também, considerar que a discriminação em relação às mulheres é um fato e pode gerar ou intensificar barreiras no seu acesso e permanência no espaço acadêmico.

Amanda Paschoal, artista, pessoa com autismo e ativista na pauta dos direitos das pessoas com autismo, publica em 31 de agosto de 2018 uma palestra no YouTube, na qual questiona a primazia masculina do autismo de 1:4 e discute a invisibilidade do autismo feminino. Ela faz um alerta para a falta de inclusão das mulheres nas pesquisas sobre autismo e como essa questão trouxe critérios limitados para o diagnóstico de autismo, não considerando a diferença de características das mulheres em relação aos homens, consequentemente a dificuldade de diagnóstico das pessoas do sexo feminino.

No que se refere à etnia/raça, a pesquisa aponta a primazia da etnia/raça branca dos estudantes no ensino superior, tanto dos estudantes com TEA quanto dos estudantes em geral matriculados em 2016 (INEP, 2017). Esse fato, constatado na pesquisa, vai ao encontro da trajetória histórica de opressão, discriminação e subjugação a que é submetida a população afrodescendente, resultando em subnotificação diagnóstica de TEA em função da dificuldade de acesso à saúde e em barreiras ou impedimentos para o acesso ao ensino superior, dentre outras. Junqueira $(2007$, p. 18) afirma que a universidade se "constituiu um espaço de formação de profissionais de esmagadora maioria não negra, em uma sociedade que, historicamente, insistiu em valorizar um único componente civilizatório - simultaneamente, branco, masculino e heterossexual". Nesse contexto social opressivo surgem as "Políticas de Ações Afirmativas 
como um instrumento de reparação histórica e de promoção da igualdade racial para a população de origem negra e que se autodeclarem como pertencente a tal grupo" (Santos, 2007, p. 106). A primazia de ingresso de estudantes de etnia branca, denota que mesmo com a implementação da lei $12.711 / 2012$, conhecida como "Lei das cotas", resultado de um movimento de ação afirmativa que tenta corrigir a desigualdade de oportunidades, ainda a desigualdade permanece para os "não-brancos", merecendo maior investimento nessa pauta.

Com relação à distribuição dos estudantes com TEA por região, ao relacionar com a população regional brasileira (IBGE, 2017), o maior número de estudantes com TEA matriculados não se concentra na região mais populosa (Sudeste), mas sim na segunda região com maior número de habitantes (Nordeste).

A discriminação no recorte etnia e regionalidade está presente em vários setores sociais, como trazida por Paschoalino Silva e Santos (2017, p. 52), que afirmam que "ser branco e residir no Sudeste (em detrimento de ser negro e residir no Nordeste) aumenta o salário de ambos os gêneros". Todavia, a "média do salário-hora dos homens é superior ao das mulheres e a diferença total entre os gêneros é de 13\%, favorecendo os homens".

Todos esses marcadores sociais da diferença como gênero, classe, etnia, dentre outras, no entrelaçamento com a deficiência, provocam uma experiência única para a pessoa que vive numa sociedade discriminatória e opressiva. Esse cruzamento de diversos marcadores sociais da diferença com a deficiência, que coloca a pessoa em desvantagem social, impacta também no âmbito educacional, na construção das subjetividades de estudantes com deficiência. Liasidou (2013, p. 1. Tradução nossa) afirma que "o desajuste faz parte de uma teia emaranhada de condições sociais que subjugam certas formas de 'estudantes-sujeitos' e criam formas de manipulação de opressão e exclusão que precisam ser abordadas através de políticas e práticas educacionais relevantes".

Com o intuito de preencher a lacuna ainda existente no que se refere à inclusão universitária dos estudantes com autismo, é preciso além de ações governamentais e institucionais, o acompanhamento e avaliação em relação ao cumprimento das políticas de acesso e permanência, possibilitando a educação superior um espaço que acolha todos os estudantes.

\section{CONSIDERAÇÕES FINAIS}

A inclusão como consequência do processo iniciado na Educação Básica se torna uma bandeira política na legislação e na política de ações afirmativas, expressa em decretos, portarias e leis para a garantia do acesso e da permanência de pessoas com deficiência nas instituições de Ensino Superior. O Brasil, um país que se destaca pelo número de aportes legais que garantem o direito das pessoas em situação de vulnerabilidade, vive a contradição da não efetivação de direitos básicos por, entre outros motivos, cortes financeiros na saúde, na educação e em outros setores responsáveis por proporcionar o cumprimento desses direitos. Nesse contexto, o conservadorismo, tanto político quanto social, propicia atitudes preconceituosas, homofóbicas, racistas, capacitistas e as tornam algo natural e no embate com grupos de resistência, vários dos quais com o protagonismo de pessoas com deficiência, mulheres negras, mulheres com deficiência; ativistas lutam pela pauta dos Direitos Humanos.

É importante marcar que as legislações e ações governamentais se constituem de acordo com a cultura política vigente e o grau de organização da sociedade civil, podendo, assim, ter avanços ou retrocessos na garantia dos direitos da pessoa com deficiência.

Ao realizar o mapeamento do perfil dos estudantes com TEA no ensino superior, constata-se uma fragilidade nos dados oficiais disponíveis. Isso remete à reflexão sobre o compromisso, o processo e o controle na construção dos dados. Embora com essa limitação, a pesquisa traz de forma consistente as características do perfil sociodemográfico dos estudantes com TEA, que em sua intersecção podem produzir situações de desigualdades em maior ou menor grau e barreiras de acesso e permanência no ensino superior. Esses aspectos devem ser considerados ao se pensar políticas públicas e ações afirmativas, bem como ações visando à inclusão desses estudantes.

\section{REFERÊNCIAS}

APA - American Psychiatric Association (2014). Manual de Transtornos Mentais DSM-5. Porto Alegre: Artmed. Vol. 1. Disponível em: <http://www.niip.com.br/wp-content/ uploads/2018/06/Manual-Diagnosico-e-Estatistico-deTranstornos-Mentais-DSM-5-1-pdf.pdf>. Acesso em: 27 maio. 2017.

Brasil (1988). Constituição 1988. Dispõe sobre a Constituição da República Federativa do Brasil. Brasília: Diário Oficial da República Federativa da União.

Brasil (2008). Política Nacional de Educação Especial na Perspectiva da Educação Inclusiva. Recuperado em 02 de junho de 2018, de http://portal.mec.gov.br/arquivos/pdf/ politicaeducespecial.pdf

Brasil (2015). Plano Nacional de Educação PNE 2014-2024. Brasília: Inep.

Cerchiari, C. M.; Paganelli, R. (2018). Educação para todos: $e$ as meninas e mulheres com deficiência? Recuperado em 07 de novembro de 2018, de http://diversa.org.br/ artigos/educacao-para-todos-meninas-e-mulheres-comdeficiencia/

Dean, M.; Harwood, R. ; Kasari, C. (2017). The art of camouflage: Gender differences in the social behaviors of girls and boys with autism spectrum disorder. Autism, 
21(6), 678-689.

Decreto n. 186 de 2008 (2008, 30 de julho). Aprova o texto da Convenção sobre os Direitos das Pessoas com Deficiência e de seu Protocolo Facultativo, assinados em Nova lorque, em 30 de março de 2007. Recuperado em 02 de junho de 2018, de http://www.planalto.gov.br/ccivil_03/Congresso/ DLG/DLG-186-2008.htm

Decreto n. 3.298/1999, de 20 de dezembro de 1999 (1999, 20 de dezembro). Regulamenta a Lei n. 7.853, de 24 de outubro de 1989, dispõe sobre a Política Nacional para a Integração da Pessoa Portadora de Deficiência, consolida as normas de proteção, e dá outras providências. Brasília: Presidência da República, Casa Civil, Subchefia para Assuntos Jurídicos. Recuperado em 02 de junho de 2018, de http://www.planalto.gov.br/ccivil_03/decreto/D3298.htm

Decreto n. 6.949, de 25 de agosto de 2009 (2009, 25 de agosto). Promulga a Convenção Internacional sobre os Direitos das Pessoas com Deficiência e seu Protocolo Facultativo, assinados em Nova York, em 30 de março de 2007. Recuperado em 02 de junho de 2018, de http:// www.planalto.gov.br/ccivil_03/_ato2007-2010/2009/ decreto/d6949.htm

Decreto n. 5.296, de 02 de dezembro de 2004 (2004, 02 de dezembro). Regulamenta as Leis n. 10.048, de 8 de novembro de 2000 , que dá prioridade de atendimento às pessoas que especifica, e n. 10.098, de 19 de dezembro de 2000, que estabelece normas gerais e critérios básicos para a promoção da acessibilidade das pessoas portadoras de deficiência ou com mobilidade reduzida, e dá outras providências. Brasília: Presidência da República, Casa Civil, Subchefia para Assuntos Jurídicos. Recuperado em 02 de junho de 2018, de http://www.planalto.gov.br/ ccivil_03/_ato2004-2006/2004/decreto/d5296.htm

Decreto n. 7.612, de 17 de novembro de 2011 (2011, 17 de novembro). Institui o Plano Nacional dos Direitos da Pessoa com Deficiência - Plano Viver sem Limite. Brasília: Presidência da República, Casa Civil, Subchefia para Assuntos Jurídicos. Recuperado em 02 de junho de 2018, de http://www.planalto.gov.br/ccivil_03/_ato20112014/2011/decreto/d7612.htm

Dworzynski, K. ; Ronald, A. ; Bolton, P. ; Happé, F. (2012). How different are girls and boys above and below the diagnostic threshold for autism spectrum disorders? Journal of the American Academy of Child and Adolescent Psychiatry, 51(8), 788-797.

IBGE (2017). Estimativa da População Residente no Brasil e Unidades da Federação. Recuperado em 20 de janeiro de 2018, de https://www.ibge.gov.br/estatisticas/ sociais/populacao/9103-estimativas-de-populacao. html?edicao $=16985 \& \mathrm{t}=$ resultados

INEP (2016). Censo da Educação Superior: Manual do Usuário. Ministério da Educação/INEP/DEE. Recuperado em 20 de janeiro de 2018, de http://download.inep.gov.br/ educacao_superior/censo_superior/documentos/2016/ notas_sobre_o_censo_da_educacao_superior_2016.pdf

INEP (2017). Microdados: Censo da Educação Superior 2016.
Recuperado em 20 de janeiro de 2018, de http://portal. inep.gov.br/microdados

Junqueira, R. D. (2007). Prefácio. In Lopes, M. A.; Braga, M. L. (Eds.), Acesso e Permanência da população negra no ensino superior (pp. 17-48). Brasília, DF: Ministério da Educação. Recuperado em 25 de dezembro de 2017, de http:// unesdoc.unesco.org/images/0015/001545/154587por.pdf

Lakatos, E. M.; Marconi, M. de A. (2005). Fundamentos de metodologia científica. São Paulo: Atlas.

Lei n. 9.394, de 20 de dezembro de 1996 (1996, 20 de dezembro). Estabelece as diretrizes e bases da educação nacional. Brasília: Presidência da República; Casa Civil; Subchefia para Assuntos Jurídicos. Recuperado em 02 de junho de 2018, de http://www.planalto.gov.br/ccivil_03/ LEIS/L9394.htm

Lei n. 11.096, de 13 de janeiro de 2005 (2005, 13 de janeiro). Institui o Programa Universidade para Todos - PROUNI, regula a atuação de entidades beneficentes de assistência social no ensino superior; altera a Lei no 10.891 , de 9 de julho de 2004, e dá outras providências. Brasília: Presidência da República; Casa Civil; Subchefia para Assuntos Jurídicos. Recuperado em 02 de junho de 2018, de http://www.planalto.gov.br/ccivil_03/_Ato20042006/2005/Lei/L11096.htm

Lei n. 12.711, de 29 de agosto de 2012 (2012, 29 de agosto). Dispõe sobre o ingresso nas universidades federais e nas instituições federais de ensino técnico de nível médio e dá outras providências. Diário Oficial da União. Recuperado em 27 de outubro de 2019, de http://www.planalto.gov. br/ccivil_03/_ato2011-2014/2012/lei/I12711.htm

Lei n. 12.764, de 27 de dezembro de 2012 (2012, 27 de dezembro). Institui a Política Nacional de Proteção dos Direitos da Pessoa com Transtorno do Espectro Autista; e altera o § 3o do art. 98 da Lei no 8.112, de 11 de dezembro de 1990. Brasília: Presidência da República; Casa Civil; Subchefia para Assuntos Jurídicos. Recuperado em 02 de junho de 2018, de http://www.planalto.gov.br/ ccivil_03/_ato2011-2014/2012/lei/l12764.htm

Lei n. 13.005, de 25 de junho de 2014 (2014, 25 de junho). Aprova o Plano Nacional de Educação - PNE e dá outras providências. Brasília: Presidência da República; Casa Civil; Subchefia para Assuntos Jurídicos. Recuperado em 02 de junho de 2018, de http://www.planalto.gov.br/ CCIVIL_03/_Ato2011-2014/2014/Lei/L13005.htm

Liasidou, A. (2013). Intersectional understandings of disability and implications for a social justice reform agenda in education policy and practice. Disability \& Society, 28(3), 299-312.

Martins, S. E. S. O.; Leite, L. P.; Ciantelli, A. P. C. (2018). Mapeamento e análise da matrícula de estudantes com deficiência em três Universidades públicas brasileiras. Psicologia Escolar e Educacional, 22(spe), 15-23. https:// dx.doi.org/10.1590/2175-35392018033

Ministério da Educação [MEC] (2008). Edital do Programa Incluir 04/2008. Brasília: Diário Oficial da União. Recuperado em 22 de junho de 2018, de http://portal.mec.gov.br/index. 
php?option=com_docman\&view=download \&alias $=816$ incluir-propostas-pdf\&category_slug=documentospdf\&ltemid=30192

Paschoalino, P. A. T.; Silva, W. P. da; Santos, M. P. dos. (2017). Discriminação de gênero no mercado de trabalho brasileiro: uma análise para o ano 2015. Revista Econômica Do Nordeste, 48(3), 43-54.

Portaria n. 1.679, de 02 de dezembro de 1999 (1999, 02 de dezembro). Dispõe sobre requisitos de acessibilidade de pessoas portadoras de deficiências, para instruir os processos de autorização e de reconhecimento de cursos e de credenciamento de instituições.

Santos, J. R. J. (2007). As Estratégias de Estar e Permanecer da Juventude Negra na Universidade: representações e percepções dos(as) estudantes da Ufal. In Lopes, M. A.; Braga, M. L. (Eds.), Acesso e Permanência da população negra no ensino superior (pp. 89-112). Brasília, DF: Ministério da Educação. Recuperado em 12 de maio de 2018, de http://unesdoc.unesco.org/ images/0015/001545/154587por.pdf

Saxe, A. (2017). The Theory Of Intersectionality: A New Lens For Understanding The Barriers Faced By Autistic Women. Canadian Journal of Disability Studies, 6(4), 153-178.

Silva, K. C. (2016). Condições de Acessibilidade na Universidade: o ponto de vista de estudantes com deficiência. Dissertação de mestrado, Universidade Estadual Paulista, São Paulo. Recuperado em 12 de maio de 2018, de http://hdl.handle. net $/ 11449 / 138845$

United Nations. Committee on the Rights of Persons with Disabilities [CRPD] (2016). General comment No. 3 (2016), Article 6: Women and girls with disabilities, 2 September 2016, CRPD/C/GC/3. Recuperado em 12 de maio de 2018, de https://www.refworld.org/docid/57c977344.html

Walker, N. (2014). Neurodiversity: Some Basic Terms \& Definitions. Recuperado em 8 de novembro de 2017, de http://neurocosmopolitanism.com/neurodiversity-somebasic-terms-definitions/

Recebido: 11 de dezembro de 2018 Aprovado: 27 de novembro de 2019 